\title{
Marked Improvement of Severe Lung Immunopathology by Influenza-Associated Pneumococcal Superinfection Requires the Control of Both Bacterial Replication and Host Immune Responses
}

\author{
Daniela Damjanovic, ${ }^{*}$ Rocky Lai, ${ }^{*}$ Mangalakumari Jeyanathan, ${ }^{*}$ Cory M. Hogaboam, ${ }^{\dagger}$ and Zhou Xing*
}

\begin{abstract}
From the Department of Pathology and Molecular Medicine,* McMaster Immunology Research Centre, M.G. DeGroote Institute for Infectious Disease Research, McMaster University, Hamilton, Ontario, Canada; and the Department of Pathology, ${ }^{\dagger}$ University of Michigan Medical School, Ann Arbor, Michigan
\end{abstract}

\begin{abstract}
CME Accreditation Statement: This activity ("ASIP 2013 AJP CME Program in Pathogenesis") has been planned and implemented in accordance with the Essential Areas and policies of the Accreditation Council for Continuing Medical Education (ACCME) through the joint sponsorship of the American Society for Clinical Pathology (ASCP) and the American Society for Investigative Pathology (ASIP). ASCP is accredited by the ACCME to provide continuing medical education for physicians.
\end{abstract}

The ASCP designates this journal-based CME activity (“ASIP 2013 AJP CME Program in Pathogenesis”) for a maximum of 48 AMA PRA Category 1 Credit(s) ${ }^{\mathrm{TM}}$. Physicians should only claim credit commensurate with the extent of their participation in the activity.

CME Disclosures: The authors of this article and the planning committee members and staff have no relevant financial relationships with commercial interests to disclose.

Accepted for publication

May 13, 2013.

Address correspondence to

Zhou Xing, M.D., Ph.D.,

Department of Pathology and

Molecular Medicine, McMaster

University, 1280 Main St W,

Room 4012-MDCL, Hamilton,

Ontario, Canada L8S 4K1.

E-mail: xingz@mcmaster.ca.

\begin{abstract}
Bacterial superinfection and associated lung immunopathology are major contributors to hospitalizations and mortality after influenza. However, the underlying mechanisms and effective intervention strategies remain poorly defined. By using a model of influenza and pneumococcal superinfection, we found that dual-infected animals experienced rapid weight loss and succumbed to infection. Bacterial outgrowth, dysregulated cytokines, including keratinocyte-derived chemokine and macrophage inflammatory protein 2, and severe lung neutrophilia and immunopathology were linked to the poor clinical outcome. In vivo neutralization of highly induced macrophage inflammatory protein 2 did not affect clinical outcome, bacterial loads, or lung immunopathology. On the other hand, in vivo neutrophil depletion did not alter the clinical outcome and bacterial burden, although it moderately improved lung immunopathology. Treatment with a bacteriostatic antibiotic, azithromycin, alone significantly improved clinical outcome and bacterial clearance, but failed to reduce lung immunopathology. In comparison, treatment with a global inflammation inhibitor, dexamethasone, alone failed to alter clinical outcome, bacterial infection, and immunopathology, despite its moderate reducing effects on neutrophilic and cytokine responses. In contrast, combined treatment with both azithromycin and dexamethasone best improved clinical outcome, bacterial clearance, lung cellular and cytokine responses, and immunopathology. Our study suggests that marked improvement of clinical outcome and lung immunopathology caused by bacterial superinfection requires the control of both bacterial infection and aberrant host immune responses. Our findings hold implications in clinical management for influenzaassociated bacterial superinfections. (Am J Pathol 2013, 183: 868-880; http://dx.doi.org/10.1016/ j.ajpath.2013.05.016)
\end{abstract}

Influenza remains one of the leading causes of deaths from respiratory tract infections. Influenza predisposes to secondary bacterial superinfection that often occurs during the recovery phase from influenza and accounts for significant hospitalizations and mortality. For instance, during the
Spanish flu pandemic of 1918, an estimated 100 million people died and the secondary bacterial pneumonia was

Supported by funds from the Canadian Institutes of Health Research and the Ontario Thoracic Society. 
a common cause of death. ${ }^{1-4}$ Although the influenza virus that causes seasonal flu is less virulent and lethal, most hospitalizations and mortality are due to bacterial superinfections or exacerbations of underlying disease. ${ }^{1}$ With the looming threat of a highly pathogenic influenza virus pandemic and increasing bacterial antibiotic resistance, it is imperative that pandemic preparedness includes not only influenza vaccines and antivirals, but also well-developed protocols to fight bacterial superinfections. ${ }^{5,6}$

Seasonal influenza infection alone typically causes a transient illness in otherwise healthy individuals, and viral clearance is achieved by 7 to 10 days after infection. ${ }^{7}$ Bacterial superinfections often occur within the first 2 weeks of influenza infection, and are caused primarily by Streptococcus pneumoniae, Staphylococcus aureus, or Haemophilus influenzae. ${ }^{6,8}$ S. pneumoniae is the most common bacterial respiratory tract pathogen and is the fifth leading cause of death worldwide. ${ }^{9}$ Host defense against the bacterium involves complement-mediated phagocytosis by alveolar macrophages and neutrophils, followed by clearance of apoptotic neutrophils by macrophages. ${ }^{9-11}$ Several mechanisms have been identified to mediate influenza-increased susceptibility to bacterial superinfection, including airway epithelial damage, upregulation and exposure of adhesion receptors, changes in airway function, modification of the cytokine milieu, and impaired innate immune cell function. ${ }^{1,2,8,12}$

In addition to impaired bacterial clearance, deleterious lung immunopathology is a prominent feature of influenza-associated bacterial superinfection, characterized by massive neutrophilic infiltration and suppurative bronchopneumonia. ${ }^{6,13-16}$ However, the mechanisms underlying such excessive immunopathology have remained poorly understood. Mouse models of influenza and bacterial superinfection have been used to recapitulate the clinical histopathological findings. Immunopathology in the lung of murine models is conventionally defined as the major histopathological changes resulting from an excessive host immune response, including inflammatory infiltration (neutrophilic and mononuclear cell infiltration) and consolidation and lung tissue injury (airway epithelium damage, hyperplasia and metaplasia, necrosis, and hemorrhage) that may negatively affect the host's clinical performance, such as body weight maintenance and respiratory tract function. ${ }^{6}$ Mounting evidence suggests a role for the ongoing inflammatory responses to influenza and uncontrolled bacterial replication, resulting in excessive neutrophilic infiltration and tissue injury. ${ }^{6,17-19}$ However, important questions still remain about whether the poor clinical outcome after bacterial superinfection is due to lung immunopathology, uncontrolled bacterial replication, or both, and whether these two events can be uncoupled and effectively controlled by using various intervention strategies. ${ }^{6}$

During influenza epidemics and pandemics, the use of antibiotic is the mainstay of treatment against bacterial superinfections. ${ }^{12}$ However, to attenuate detrimental immunopathology, treatment protocols must be carefully selected.
For instance, recent clinical and experimental data suggest that treatment with $\beta$-lactam bacteriolytic antibiotics may worsen the outcome of hospitalized patients or lung immunopathology. ${ }^{20-22}$ The use of bacteriostatic macrolide antibiotics that inhibit bacterial protein synthesis may improve lung immunopathology and control bacterial infection, whereas other strategies aimed to restore impaired innate immunity may, in fact, exacerbate immunopathology. ${ }^{6,21}$ On the other hand, although corticosteroids are used in severe cases of influenza infection or communityacquired pneumonia, there is still no consensus on their benefit, particularly in cases of influenza-associated bacterial superinfections. ${ }^{23-29}$

In our current study, we have established a murine model of acute respiratory tract influenza infection and S. pneumoniae superinfection to investigate the mechanisms of severe lung immunopathology and the intervention strategies for effective improvement of clinical outcomes and immunopathology. Our study identifies uncontrolled bacterial outgrowth, dysregulated cytokine and chemokine responses, and excessive neutrophil infiltration in the lungs to be the main contributors to deleterious lung immunopathology and death. Although the use of a bacteriostatic macrolide antibiotic alone effectively controlled bacterial replication and improved clinical outcome, it failed to significantly reduce lung immunopathology. On the other hand, the use of dexamethasone (DEX) alone had no impact on bacterial clearance and only a minimum beneficial effect on immunopathology. Strikingly, the use of antibiotic and DEX in combination led to the best clinical outcome, with markedly improved survival, bacterial clearance, and lung immunopathology. Therefore, our study reveals that the mechanisms of severe lung immunopathology by influenza-associated bacterial superinfection are multifactorial and are, in part, independent of bacterial burden. Effective intervention strategies need to involve the effective control of both bacterial infection and aberrant host immune responses.

\section{Materials and Methods}

\section{Mice}

Female 7- to 10-week-old C57BL/6 mice were purchased from Charles River Laboratories (Wilmington, MA). Mice were housed in specific pathogen-free level facilities at the McMaster University Central Animal Facility (Hamilton, ON, Canada). For all experiments, mice were euthanized by exsanguination of the abdominal artery under anesthesia. All experiments were conducted in accordance with the animal research ethics board of McMaster University.

\section{Infectious Agents}

A mouse-adapted strain of influenza A/FM/1/47 (H1N1) was prepared and used as previously described. ${ }^{7,30}$ A clinical isolate $S$. pneumoniae serotype 3 (ATCC 6303; ATCC, Manassas, VA) was prepared by plating frozen stock on 
blood-agar plates and incubating overnight, then culturing the resultant colonies for approximately 5 hours at $37^{\circ} \mathrm{C}$ in $5 \% \mathrm{CO}_{2}$ in Todd Hewitt broth to midlogarithmic phase (BD Biosciences, San Jose, CA). The bacteria were harvested and resuspended in PBS. The infectious dose was verified by plating 10 -fold dilutions on blood-agar plates.

\section{Heterologous Infection Model}

Mice anesthetized by inhalation of isoflurane were infected intranasally with $10^{5}$ plaque-forming units of influenza virus in $20 \mu \mathrm{L}$ of PBS (or PBS only as control). After 7 days, mice were infected intratracheally with $10^{3}$ colony-forming units (CFUs) of $S$. pneumoniae in $40 \mu \mathrm{L}$ of PBS (or PBS only as control). Mice were monitored for changes in body weight and other disease symptoms after influenza infection and then at 20,48, 60, and 72 hours after S. pneumoniae infection. Moribund mice were terminated (usually by 60 hours after Streptococcus infection), and the end point was defined as $20 \%$ loss of the initial body weight (before influenza infection), which occurred between 60 and 72 hours after Streptococcus infection for all dual-infected mice.

\section{Determination of Influenza and Streptococcus Load in} Tissue

Influenza levels in the lung were quantified at 7 days after flu by plaque-forming assay using Madin-Darby canine kidney cells, as previously described. ${ }^{7}$ Levels of streptococcus in the lung, spleen, heart, liver, kidney, and brain were determined by homogenizing the tissues in PBS, plating serial dilutions on blood-agar plates, and incubating overnight at $37^{\circ} \mathrm{C}, 5 \% \mathrm{CO}_{2}$. Colonies were counted and calculated as CFUs per whole organ.

\section{Pulmonary Histopathological Analysis}

Lungs were inflated with $10 \%$ formalin and kept in $5 \mathrm{~mL}$ of $10 \%$ formalin for at least 72 hours. Tissue sections were stained with $\mathrm{H} \& \mathrm{E}$ for histological examination. Blinded lung histopathological scoring was performed by using a semiquantitative method ranging from 1 to 10 , with 10 being the most extensive pathology (D.D.).

\section{BAL and Lung Cell Isolation}

Airway luminal cells were collected by bronchoalveolar lavage (BAL) of the lungs by using a standard procedure, as previously described. ${ }^{7}$ BAL fluids were stored at $-20^{\circ} \mathrm{C}$ until cytokine measurement. Cell pellets were resuspended in complete RPMI medium (RPMI 1640 medium supplemented with $10 \%$ fetal bovine serum, $1 \%$ penicillin-streptomycin, and $1 \% \mathrm{~L}$-glutamine). Mononuclear cells were isolated from lung tissue, as previously described. ${ }^{7}$ Briefly, the lungs were cut into small pieces and incubated in $10 \mathrm{~mL}$ of $150 \mathrm{U} / \mathrm{mL}$ collagenase type I (Sigma-Aldrich, St. Louis, MO) for 1 hour at $37^{\circ} \mathrm{C}$, with agitation. The lung pieces were then crushed through $40-\mu \mathrm{m}$ basket filters, red blood cells were lysed with ammonium-chloride-potassium lysis buffer $(0.15 \mathrm{~mol} / \mathrm{L}$ $\mathrm{NH}_{4} \mathrm{Cl}, 1 \mathrm{~mol} / \mathrm{L} \mathrm{KHCO}_{3}$, and $0.1 \mathrm{mmol} / \mathrm{L} \mathrm{Na}_{2}$ EDTA, $\mathrm{pH}$ 7.4), and the remaining cells were resuspended in complete RPMI medium.

\section{Flow Cytometric Analysis}

Flow cytometry was performed on BAL and lung cells. Cells were incubated for 15 minutes with the CD16/CD32 Fc block antibody, and then stained with extracellular antibodies (BD Biosciences unless otherwise stated) for antigen-presenting cells [APC-Cy7-anti-CD45 and Alexa Fluor 700-antimajor histocompatibility complex II (eBioscience, San Diego, CA), Pacific Orange-anti-Gr1 (Invitrogen, Carlsbad, $\mathrm{CA}), \mathrm{APC}-$ anti-CD11c, and phosphatidylethanolamineCy7-anti-CD11b], natural killer cells (V450-anti-CD3 and phosphatidylethanolamine-anti-NK1.1), and T cells (V450 anti-CD3, APC-Cy7-anti-CD4, and phosphatidylethanolamine-Cy7-anti-CD8), in separate wells for each population. Stained cells were run on the LSRII flow cytometer (BD Biosciences) and analyzed using FlowJo software version 8.7 (Tree Star, Inc., Ashland, OR).

\section{MP0 Assay}

Myeloperoxidase (MPO) was measured in total lung tissue as previously described. ${ }^{19,31}$ Briefly, lungs were homogenized in $1 \mathrm{~mL}$ PBS, the pellets were resuspended in hexadecyltrimethylammonium bromide buffer (Sigma-Aldrich, Oakville, ON, Canada) to a concentration of $100 \mathrm{mg} / \mathrm{mL}$ and homogenized again, and the supernatant was frozen at $-80^{\circ} \mathrm{C}$ until the assay (performed $\leq 7$ days later). Supernatant $(10 \mu \mathrm{L})$ was added to $200 \mu \mathrm{L}$ of the reaction mixture [16.7 mg o-dianisidine (Sigma-Aldrich, St. Louis, MO), 90 $\mu \mathrm{L}$ distilled $\mathrm{H}_{2} \mathrm{O}, 10 \mu \mathrm{L}$ of $50 \mathrm{mmol} / \mathrm{L}$ dibasic potassiumphosphate buffer (EMD Chemicals, Gibbstown, NJ), and $50 \mu \mathrm{L}$ of $1 \% \mathrm{H}_{2} \mathrm{O}_{2}$ ] in a 96-well flat-bottom plate. Absorbance was measured at $450 \mathrm{~nm}$ in a spectrophotometer at 1minute intervals. MPO activity is expressed as units per gram of lung tissue, where $1 \mathrm{U}$ MPO is defined as the amount of enzyme capable of degrading $1 \mu \mathrm{mol} \mathrm{H}_{2} \mathrm{O}_{2} /$ minute at room temperature.

\section{Neutrophil Phagocytosis Assay}

Mice were sacrificed at 54 hours after Streptococcus, and total lung cells were isolated. Freshly grown (to midlogarithmic phase) $S$. pneumoniae was stained with 10 $\mu \mathrm{mol} / \mathrm{L}$ carboxyfluorescein succinimidyl ester (CFSE; Life Technologies Inc., Burlington, ON, Canada) for 1 hour at room temperature, and then opsonized with naïve serum for 30 minutes at $37^{\circ} \mathrm{C}, 5 \% \mathrm{CO}_{2}$. Lung cells and labeled $S$. pneumoniae were incubated in 6-well plates at a multiplicity of infection of 10 for 1 or 2 hours at $37^{\circ} \mathrm{C}, 5 \% \mathrm{CO}_{2}$. 
Cells were removed from the plates, transferred to $5-\mathrm{mL}$ polystyrene tubes, washed with PBS, stained for neutrophil surface markers, and analyzed with flow cytometry. Results are represented as frequency of $\mathrm{CD} 11 \mathrm{~b}^{+} \mathrm{Gr} 1^{+}$cells that were CFSE positive.

\section{Cytokine and Chemokine Quantification}

Levels of cytokines and chemokines in BAL fluid and lung homogenates were quantified using Luminex multianalyte technology (Luminex Molecular Diagnostics, Toronto, ON, Canada), according to the manufacturer's protocols.

\section{In Vivo MIP-2 Chemokine Neutralization and Neutrophil Depletion}

For macrophage inflammatory protein 2 (MIP-2) neutralization, $200 \mu \mathrm{g}$ of rabbit anti-murine MIP-2 serum or normal rabbit serum as control was injected i.p. into dual-infected mice ( 7 days after influenza) at 10 hours before Streptococcus, and at 20 and 40 hours after Streptococcus. Mice were sacrificed at 60 hours after Streptococcus. For neutrophil depletion, anti-Ly6G (1A8) antibody (University of California, San Francisco, Monoclonal Antibody Core, San Francisco, CA) or total rat IgG as control was given to dualinfected mice as follows: at 8 hours before Streptococcus, $200 \mu \mathrm{g}$ i.p.; at 16 hours after Streptococcus, $200 \mu \mathrm{g}$ i.p. +100 $\mu \mathrm{g}$ intranasally; and at 40 hours after Streptococcus, $350 \mu \mathrm{g}$ i.p. Mice were sacrificed at 60 hours after Streptococcus.

\section{Antibiotic and Corticosteroid Treatment}

Dual-infected mice were injected with $4 \mathrm{mg} / \mathrm{kg}$ of the corticosteroid, DEX (PCCA, Houston, TX), i.p. at 15 and 29 hours after Streptococcus. Other mice were injected with $10 \mathrm{mg} / \mathrm{kg}$ of the antibiotic, azithromycin (AZI; Sandoz Canada Inc., Boucherville, QC, Canada), i.p. at 30 hours and with $5 \mathrm{mg} / \mathrm{kg}$ at 44 hours after Streptococcus. Some mice were treated with both DEX and AZI at the indicated time points, whereas control mice were given only PBS at those time points.

\section{Statistical Analysis}

To determine significance between infection groups, a Student's $t$-test was used for two-sample comparisons. Otherwise, a one-way analysis of variance and Tukey's post hoc test were performed with Prism version 5 (GraphPad Software, Inc., La Jolla, CA). $P<0.05$ was regarded as statistically significant.

\section{Results}

\section{Influenza Infection Increases Susceptibility to Pneumococcal Superinfection}

To determine the effect of influenza infection on subsequent bacterial superinfection, mice were infected intranasally with a nonlethal dose of influenza virus. By 7 days after
A

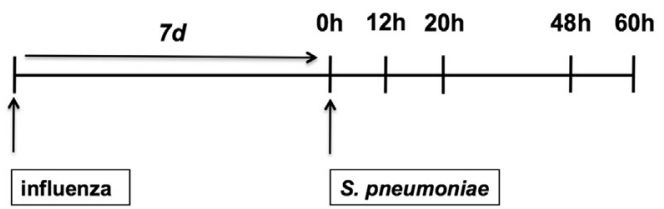

B

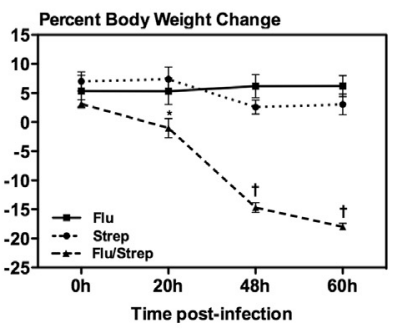

C

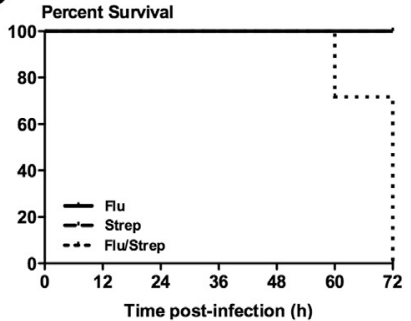

Figure 1 Influenza infection causes increased susceptibility to pneumococcal superinfection. A: Experimental scheme. Female $\mathrm{C} 57 \mathrm{BL} / 6$ mice were infected with $10^{5}$ plaque-forming units of influenza virus and 7 days (d) later with $10^{3}$ CFUs of S. pneumoniae. B: Average percentage body weight change. C: Percentage survival. Results are from multiple experiments ( $n=10$ to 44 per group per time point). D: Lung and spleen bacterial load in Strep (white bars) and Flu/Strep (black bars) mice was measured with a CFU assay at 20,48 , and 60 hours (h) after Streptococcus infection. Results are from two to four independent experiments $(n=10$ to 34 per group per time point). E: Heart, liver, kidney, and brain bacterial load in Flu/ Strep mice was measured at 60 hours after Streptococcus. Results are from one to two experiments $(n=6$ to 10). Data are expressed as means \pm SEM. ${ }^{*} P<0.0005$.

D

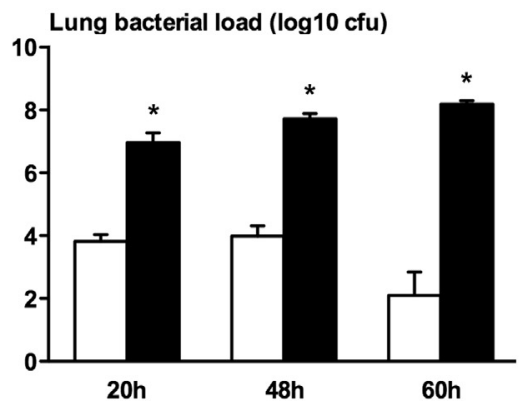

Spleen bacterial load (log10 cfu)

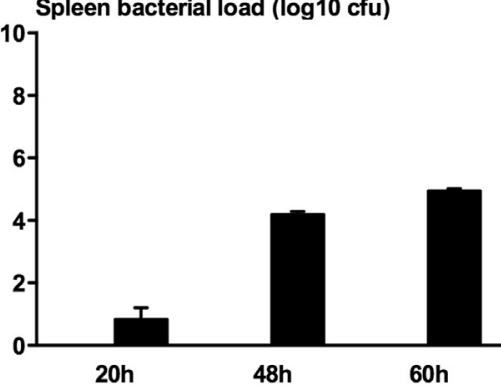

E

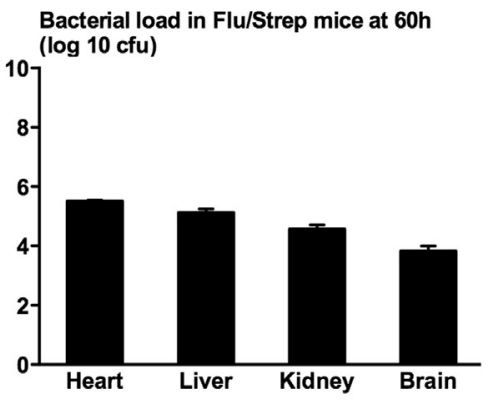


Table 1 Semiquantification of Histopathological Changes in the Lung

\begin{tabular}{|c|c|c|c|c|c|c|c|c|c|}
\hline \multirow[b]{2}{*}{ Variable } & \multicolumn{3}{|c|}{ Flu (hours) } & \multicolumn{3}{|c|}{ Strep (hours) } & \multicolumn{3}{|c|}{ Flu/Strep (hours) } \\
\hline & 20 & 48 & 60 & 20 & 48 & 60 & 20 & 48 & 60 \\
\hline Neutrophilia & ND & ND & - & + & + & + & ++ & ++++ & +++++ \\
\hline Injury & ND & ND & + & - & $-/+$ & $-/+$ & ++ & ++++ & +++++ \\
\hline
\end{tabular}

Tissue neutrophilia, overall lung inflammation (mononuclear cell infiltration), and lung injury (consolidation, degeneration of airway epithelium, necrosis, hemorrhaging, and metaplasia) were assessed. Results are representative of three to five experiments ( $n=5$ to 10 mice per group per time point).

ND, no data; + , minimal; ++ , slight; ++++ , marked; +++++ , severe; - , absent.

infection, the virus was almost completely cleared from the lungs (data not shown). At this point, mice were infected intratracheally with a small dose $\left(10^{3} \mathrm{CFUs}\right)$ of $S$. pneumoniae and sacrificed at various time points after infection (Figure 1A). Dual-infected mice are designated as Flu/Strep, whereas the mice that were infected only with influenza are designated Flu and mice only infected with $S$. pneumoniae are designated Strep. Body weight changes and survival were monitored as a measure of overall illness or clinical outcome. Flu mice experienced no weight loss, and all groups of mice gained approximately $5 \%$ of initial body weight over the course of 7 days by the time point of Streptococcus infection at 0 hours (Figure 1B). Over the next 60 hours, Flu mice continued to gain weight and Strep mice lost minimal weight $(<5 \%)$, whereas Flu/Strep mice, on average, had almost reached the end point ( $20 \%$ weight loss) (Figure 1B). Some Flu/Strep mice did reach the end point by 60 hours after Streptococcus (28\% lethality), and $100 \%$ lethality was seen by 72 hours (Figure 1C).

Consistent with the illness and lethality, the Flu/Strep mice had significantly higher lung bacterial loads than the Strep mice at all time points (Figure 1D). The bacterial load in the lungs of Strep mice decreased between 48 and 60 hours after infection (Figure 1D) and was cleared by 5 days (data not shown), whereas the Flu/Strep mice had consistently increasing bacterial loads up to the end point at 60 hours (Figure 1D). Bacterial dissemination past the lung was not observed in Strep mice, whereas Flu/Strep mice had increasing levels of bacterial burden in the spleen from 20 to 60 hours after Streptococcus (Figure 1D), and marked systemic dissemination to other organs, including the heart, liver, kidney, and brain at 60 hours (Figure 1E). These results show that infection with a nonlethal dose of influenza increases susceptibility to streptococcus infection, causing an otherwise small inoculum of $S$. pneumoniae to lead to bacterial outgrowth, wide systemic dissemination, and $100 \%$ lethality within 3 days after infection.

To determine whether the influenza-increased susceptibility to bacterial superinfection is sustained $>7$ days, mice were infected with $S$. pneumoniae 11 or 21 days after influenza and sacrificed at 60 hours after Streptococcus. After infection at 11 days after influenza, Flu/Strep mice still experienced significantly higher bacterial loads in the lung and systemic dissemination to the spleen compared with Strep mice, although there were no differences observed at
21 days (data not shown). This suggests that the effects of influenza on susceptibility to superinfection are sustained for at least to 11 days after the initial influenza infection.

\section{Severe Lung Immunopathology by Pneumococcal Superinfection}

To further investigate the cause of illness and death in Flu/ Strep mice, in addition to the bacterial outgrowth, dissemination, and severe weight loss (Figure 1), we examined histopathological changes in the lung. At 9 to 10 days after influenza infection, when the virus is cleared (data not shown), the Flu mice had minimal residual inflammation in the lung (Table 1). After low-dose S. pneumoniae infection, the Strep mice displayed minimal lung inflammation, with only slight neutrophil infiltration seen at 48 and 60 hours
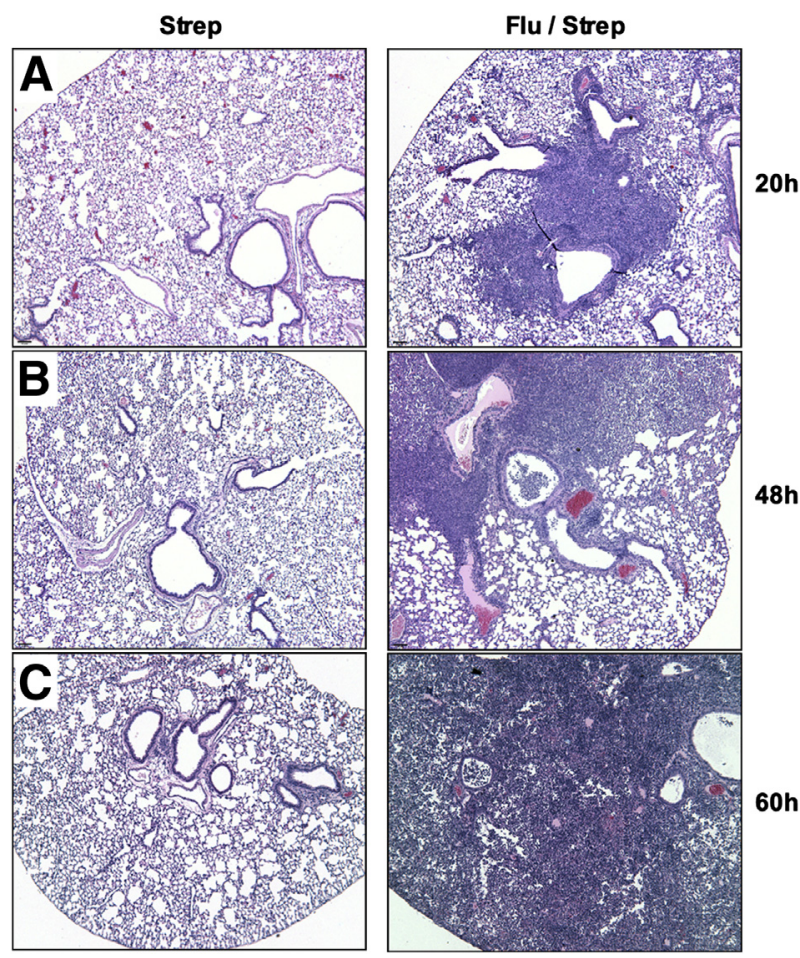

Figure 2 Severe lung immunopathology after pneumococcal superinfection in influenza-infected hosts. Histopathological changes were examined by H\&E staining in the lungs of Strep and Flu/Strep mice at 20 (A), 48 (B), and 60 (C) hours (h) after Streptococcus infection. Results are representative of three to five experiments ( $n=5$ to 10 per group per time point). Original magnification, $\times 5$. 
after infection (Figure 2, B and C, and Table 1). In contrast, $S$. pneumoniae superinfection in Flu/Strep mice caused severe lung immunopathology and tissue injury, which increased from 20 hours after infection to the end point at 60 hours (Figure 2, A-C, and Table 1). Immunopathology was associated with excessive neutrophilia, including the appearance of apoptotic and necrotic neutrophils, particularly at 60 hours (Figure 2C). Further evidence of lung injury included large areas of consolidation spreading to whole lung lobes by 60 hours after Streptococcus, degeneration and sloughing of airway epithelium, hemorrhaging, metaplasia, and plugged airways filled with neutrophils, cell debris, and mucus (Figure 2C). Pleuritis was evident on the lung surfaces, including excessive amounts of mucus and lung fluid exudate that filled the chest cavity (Figure 2C). These findings further support the role of influenza in predisposing to subsequent bacterial superinfection that leads to severe lung immunopathology underlying illness and death.

\section{Excessive Neutrophil Infiltration in the Lungs after Pneumococcal Superinfection}

Given severe tissue neutrophilia and immunopathology seen in the lung of Flu/Strep hosts, we further examined neutrophilic responses by quantifying neutrophils both in the BAL fluids and lung tissue at various time points by flow cytometry. Excessive neutrophil influx was observed in the BAL and lung tissue of Flu/Strep mice between 12 and 60 hours after Streptococcus, and was significantly higher than in the other groups (Figure 3A). There were no differences in macrophage and dendritic cell numbers between the groups, and $\mathrm{T}$ cell numbers were slightly lower in the Flu/Strep mice than in Flu mice at 60 hours (data not shown).

The MPO activity was also measured as an indication of neutrophil antibacterial functionality in lung homogenates at 48 and 60 hours after Streptococcus. At the 48-hour time point, although there were eightfold more neutrophils in the lungs of Flu/Strep mice compared with Strep mice (Figure 3A), the MPO activity was only fivefold higher (Figure 3B). At 60 hours after infection, MPO activity was the same between the two groups (Figure 3B), even when neutrophil numbers remained significantly (fourfold) higher in the Flu/Strep mice (Figure 3A), suggesting that neutrophil antibacterial activity on a per cell basis was impaired in the dual-infected mice. To further examine the function of neutrophils, we used an in vitro model of neutrophil phagocytosis by using CFSE-labeled bacteria and the lung cells isolated at 54 hours after Streptococcus. We found that the neutrophils from the lungs of Flu/Strep animals had a significantly decreased capability to phagocytose the bacteria compared with their counterparts from the lung of Strep animals at both time points examined (Figure 3C). These results suggest that the overwhelming tissue neutrophilia and the resulting lung immunopathology may have contributed to illness and death of dual-infected mice. In
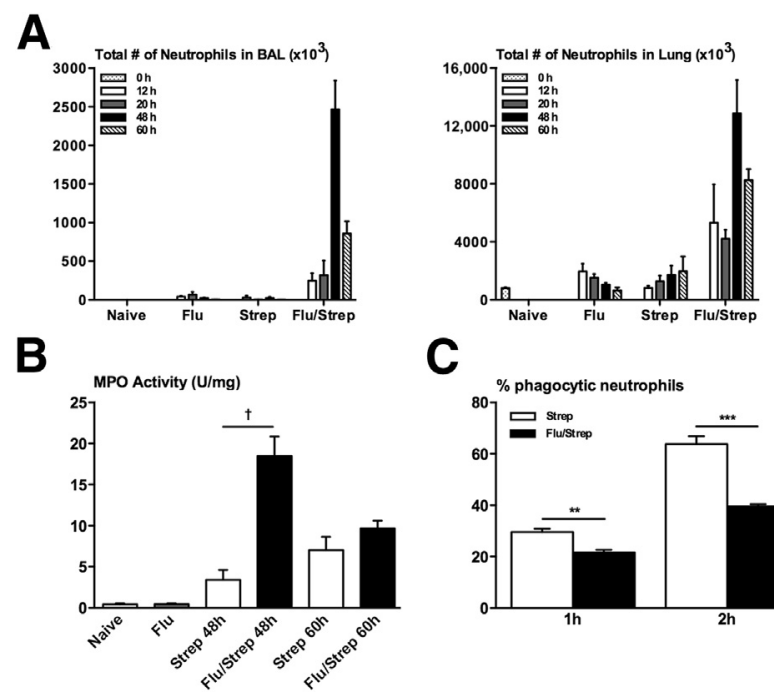

C

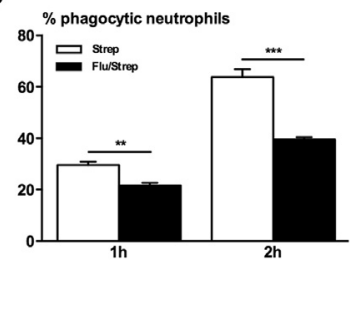

Figure 3 Neutrophil infiltration and functional impairment in the lungs after pneumococcal superinfection in influenza-infected hosts. A: Neutrophil $\left(\mathrm{CD} 11 \mathrm{~b}^{+} \mathrm{Gr}^{+}\right)$influx into the BAL and lung was assessed by flow cytometry in Naive, Flu, Strep, and Flu/Strep mice at various time points after Streptococcus infection. Results are total neutrophil numbers in the tissue compartment, from four experiments ( $n=4$ to 10 per group per time point). Data are expressed as means \pm SEM. B: Neutrophil activity was measured with a MPO assay of lung homogenates at 48 and 60 hours (h) after Streptococcus. Results are from two experiments $(n=6$ per group per time point). C: Mice were sacrificed 54 hours after Streptococcus, and lung cells were incubated with CFSE-labeled S. pneumoniae for 1 to 2 hours. Cells were stained for neutrophil markers and analyzed with flow cytometry for CFSE inclusion. Results represent the portion of all neutrophils that had phagocytosed bacteria ( $n=3$ per group), plated in duplicate for each animal and time point. Data are expressed as means \pm SEM. ${ }^{* *} P<0.01$, $* * * P<0.001$, and ${ }^{\dagger} P<0.0005$.

addition, impaired neutrophil antibacterial functionality in previous influenza-imprinted lungs could be the cause for impaired clearance of pneumococci from the lungs, leading to its systemic dissemination.

\section{Aberrant Cytokine and Chemokine Responses after Pneumococcal Superinfection}

To investigate the potential molecular mechanisms leading to overwhelming tissue neutrophilia and immunopathology of Flu/Strep mice, we examined cytokine responses in the lung. Cytokine and chemokine levels were assessed in lung homogenates at 12, 20, and 48 hours after $S$. pneumoniae infection. Flu-infected mice had low, naïve levels of all analytes measured in the lung, whereas Strep mice had slight increases in some analytes at 48 hours after infection (Figure 4). In contrast, the levels of most cytokines and chemokines measured, including interferon (IFN)- $\gamma$, tumor necrosis factor- $\alpha, \mathrm{KC}$, and MIP-2, were much higher between 20 and 48 hours in the lungs of Flu/Strep mice (Figure 4). This corresponded to the sharp increase in wide systemic bacterial dissemination (Figure 1, D and E) and the rapid weight loss observed (Figure 1B). Other cytokines and chemokines, including IFN- $\beta$, IL- $1 \beta$, granulocyte- 

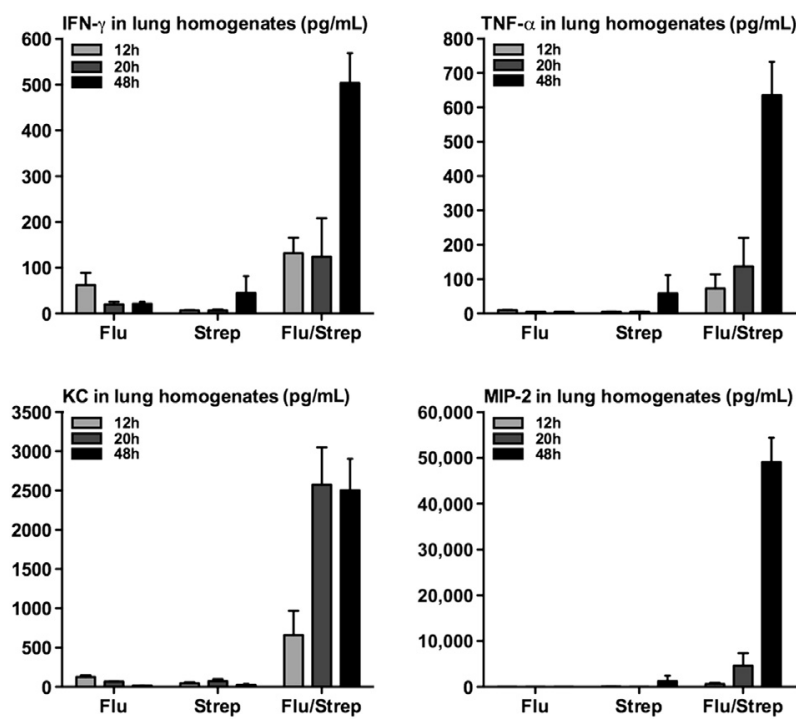

Figure 4 Dysregulated cytokine and chemokine responses in the lungs after pneumococcal superinfection in influenza-infected hosts. Cytokine and chemokine levels in lung homogenates were measured in Flu, Strep, and Flu/Strep mice at 12, 20, and 48 hours (h) after Streptococcus infection. Results are from three experiments ( $n=3$ to 4 per group per time point). Data are expressed as means \pm SEM.

macrophage colony-stimulating factor, IL-17, IL-10, monocyte chemotactic protein-1 (MCP-1), MIP-1 $\alpha$, MIP$1 \beta$, IP-10, and regulated on activation normal $\mathrm{T}$ cell expressed and secreted, were also significantly increased, whereas IL-12 and IL-15 did not increase in Flu/Strep mice (data not shown). Corresponding increases in the same analytes were observed in the BAL fluids (data not shown). The levels of the neutrophil-attracting chemokines, $\mathrm{KC}$ and MIP-2, were induced to much higher levels (up to 50,000 $\mathrm{pg} / \mathrm{mL}$ concentrations) than any other increased analytes measured, in accordance with overwhelming neutrophil influx into the lungs (Figure 3A). These data suggest that overwhelming cytokine/chemokine responses, culminating in a cytokine storm in the lungs of dual-infected animals, contributed to the influenza-induced susceptibility to lung neutrophilia, severe immunopathology, and fatal clinical outcome.

\section{Effects of MIP-2 Neutralization and Neutrophil Depletion on Lung Immunopathology and Clinical Outcome of Dual-Infected Hosts}

Chemokine overexpression (Figure 4) and excessive neutrophil influx into the lungs (Figure 3A) were characteristic of dual-infected mice, and correlated with severe lung immunopathology (Figure 2) and fatal clinical outcome (Figure 1C). We, therefore, set out to investigate whether in vivo neutralization of the neutrophil chemokine, MIP-2, which was the most highly induced analyte measured (Figure 4), would significantly dampen severe lung immunopathology and improve the clinical outcome in Flu/Strep animals. Dual-infected mice were treated with three doses of
anti-MIP-2 serum beginning at 10 hours before $S$. pneumoniae infection and were sacrificed at 60 hours. MIP-2 neutralization did not lead to an improvement in weight loss or bacterial burden compared with control mice (Supplemental Figure S1A). Furthermore, histopathological assessment showed no changes in lung immunopathology after MIP-2 neutralization compared with the control animals (Supplemental Figures S1A and S2 and Table 2). These results suggest that neutralization of one selected chemokine may be insufficient to improve lung immunopathology and clinical outcome, because other functionally redundant chemokines, such as KC, were also highly induced in Flu/Strep hosts. Based on this consideration, in separate experiments, we in vivo depleted neutrophils by using three repeated doses of anti-Ly6G antibody beginning at 8 hours before $S$. pneumoniae infection, and the mice were sacrificed at 60 hours. Although similar to MIP-2 depletion, neutrophil depletion did not lead to an improvement in body weight losses or altered bacterial burden (Supplemental Figure S1B); it led to somewhat improved lung immunopathology, although moderate lung inflammation and injury associated with residual neutrophils were still observed in the lung parenchyma (Supplemental Figures S1B and S2 and Table 2). Neutrophil depletion was fully achieved, as assessed by flow cytometry; however, residual apoptotic/necrotic neutrophils were seen in the histopathological assessment, suggesting that the depleting antibody and the flow cytometry antibody did not bind to such neutrophils. These results suggest that excessive neutrophil infiltration contributes to severe lung immunopathology and injury in Flu/Strep animals. On the other hand, increased neutrophils in the lung adds little to antibacterial host defense because they have severely impaired antibacterial activities, consistent with discordant MPO activity and decreased phagocytosis capability in Flu/ Strep animals (Figure 3, B and C).

\section{Marked Improvement of Lung Immunopathology and Clinical Outcome by Combined Antibiotic and Corticosteroid Treatment in Dual-Infected Hosts}

Our data have shown that neutrophil depletion led to only partially improved lung immunopathology, but had no altering effects on bacterial burden and clinical performance

Table 2 Assessment of Histopathological Changes in the Lung after Immunotherapy

\begin{tabular}{llll}
\hline Variable & Control & $\alpha$-MIP-2 & $\alpha$-Ly6G \\
\hline Neutrophilia & +++++ & +++++ & ++ \\
Inflammation & +++++ & +++++ & +++ \\
Injury & +++++ & +++++ & +++ \\
\hline
\end{tabular}

Tissue neutrophilia, overall lung inflammation, and lung injury were assessed in control or treated Flu/Strep mice at 60 hours after Streptococcus. Results are representative of one to two experiments ( $n=7$ to 14 mice per group).

++ , Slight; +++ , moderate; +++++ , severe. 
of Flu/Strep animals (Supplemental Figures S1B and S2 and Table 2). This observation suggests that lung immunopathology and bacterial clearance may be independently regulated on one hand, and that a significant improvement in clinical outcome of these animals may require the stringent control of both bacterial infection and lung immunopathology on the other hand. This consideration led us next to examine antibiotic and/or corticosteroid treatment options in dual-infected mice. To this end, Flu/Strep mice were treated with a bacteriostatic, macrolide antibiotic, AZI, and/or the global inflammatory/immune inhibitor corticosteroid, DEX, from 15 to 44 hours after Streptococcus and sacrificed at 60 hours (Figure 5A). Untreated (PBS) mice expectedly lost almost $20 \%$ of body weight, and some reached the end point by 60 hours; DEX-treated mice had a similarly poor clinical outcome (Figure 5B). In comparison, AZI alone treated mice stopped losing weight soon after the first dose was given, and regained weight to almost preinfection levels by 60 hours, whereas the mice treated with both DEX and AZI had the best clinical outcome with the most rapid recovery in their body weight (Figure 5B). The weight changes were significantly different between the PBS and DEX groups versus the AZI and DEX/AZI groups at the later time points, and the difference in body weight recovery rates was also significantly different between the AZI and DEX/AZI groups at 44 hours (Figure 5B). These data show that clinical outcome is most efficiently improved by treatment with the use of both a bacteriostatic antibiotic, AZI, and a global inflammatory/immune inhibitor, DEX.

To examine the possible causes leading to improved clinical outcome by AZI or DEX/AZI treatment, we first examined the bacterial burden in the lung and spleen. In accordance with improved clinical outcome, mice treated with AZI or DEX/AZI had most significantly decreased bacterial burden in the lungs and had no systemic bacterial dissemination to the spleen, whereas DEX-treated mice had the same levels of bacteria as untreated control mice (Figure 6A). We further examined the cellular and cytokine responses in the lungs of these animals. Neutrophil influx into both the BAL and lung tissue was significantly lower in AZI and DEX/AZI mice, and slightly lower in DEX mice when compared with PBS mice (Figure 6B). Despite similarly decreased numbers of neutrophils in the lungs of AZI and DEX/AZI mice, DEX/AZI lungs had significantly lower MPO activity than AZI lungs (Figure 6C). On the other hand, levels of the cytokines and chemokines, IFN- $\gamma$, tumor necrosis factor- $\alpha$, MIP- $1 \alpha$, KC, MIP-2, and MCP-1 (Figure 7), were significantly higher in the untreated PBS group compared with all other groups. Of all groups, the combined DEX and AZI treatment resulted in the greatest overall level of reduction in cytokine/chemokine responses (Figure 7), corresponding to its best-improved clinical outcome (Figure 5B) and lowest MPO activity (Figure 6C). In comparison, AZI treatment alone only moderately reduced tumor necrosis factor- $\alpha$, MIP- $1 \alpha$, and MCP-1 whereas it markedly reduced IFN- $\gamma, \mathrm{KC}$, and MIP-2
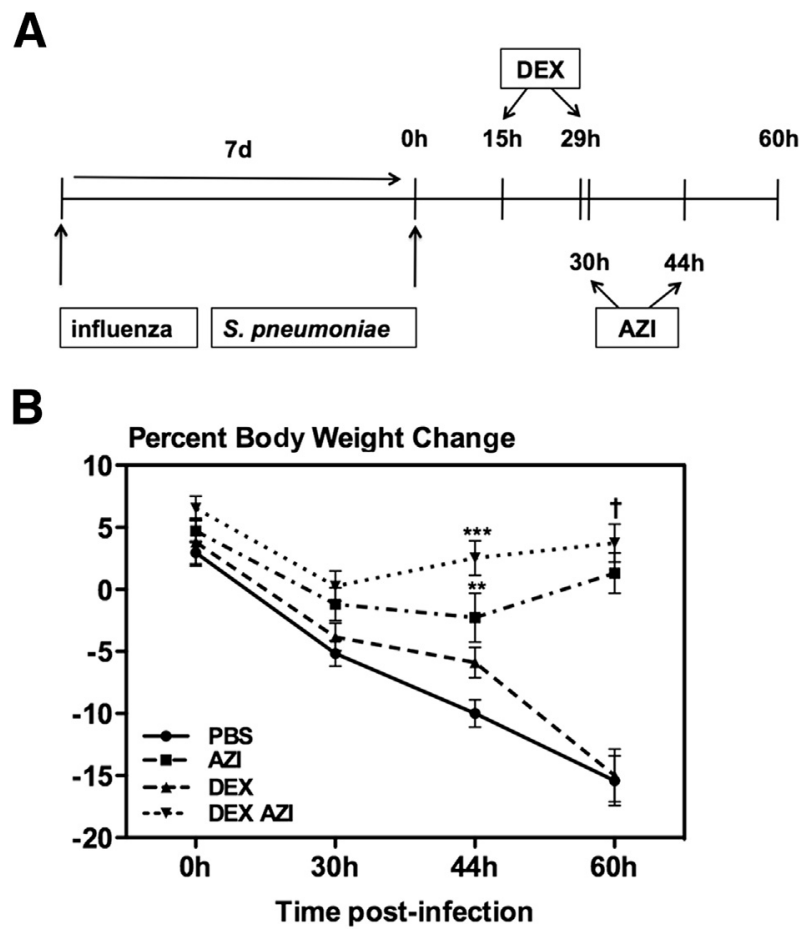

Figure 5 Combined antibiotic and corticosteroid treatment improves clinical outcome of dual-infected mice. A: Experimental scheme. Mice were infected with $10^{5}$ plaque-forming units of influenza virus and 7 days (d) later with $10^{3}$ CFUs of S. pneumoniae. DEX was given at 15 and 29 hours (h), AZI was given at 30 and 44 hours after Streptococcus, and mice were sacrificed at 60 hours. B: Average percentage body weight changes. Results are from two to three experiments ( $n=14$ to 21 per group). Data are expressed as means \pm SEM. ${ }^{* *} P<0.01,{ }^{* * *} P<0.001$, and ${ }^{\dagger} P<0.0005$ versus the PBS group.

(Figure 7). DEX treatment alone only moderately, but significantly, reduced almost all cytokines/chemokines examined (Figure 7), in contrast to its negligible modulating effect on clinical outcome (Figure 5B) and bacterial burden (Figure 6A).

On histopathological examination, we found that, corresponding with the best clinical outcome (Figure 5B), the most reduced bacterial burden (Figure 6A), the most reduced neutrophil influx and activation (Figure 6, B and C), and cytokine/chemokine responses (Figure 7) achieved by the combined DEX and AZI treatment, the apparent and dramatic improvement in lung immunopathology was observed only in DEX/AZI animals (Figure 8D and Table 3). Despite its significant improving effects on clinical outcome and bacterial burden (Figures 5 and 6), AZI treatment alone only modestly improved lung immunopathology, because substantially higher levels of inflammation and injury were observed compared with DEX/AZI treatment (Figure 8B, Supplemental Figure S2, and Table 3). A significant level of immunopathology in AZI animals persisted up to 144 hours, well beyond the point of complete bacterial clearance ( 88 hours) (data not shown). On the other hand, in accordance with unaltered clinical outcome and bacterial burden, and moderately reduced cytokine 
A

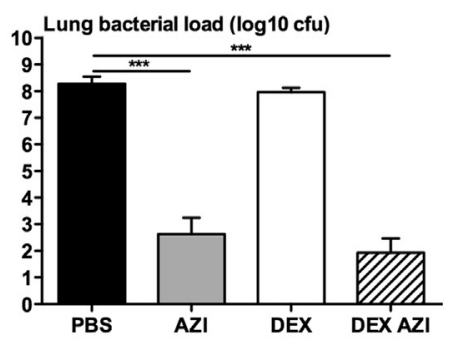

B

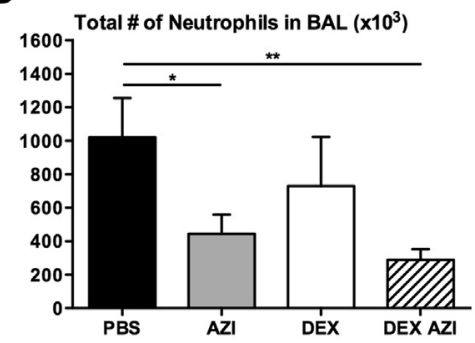

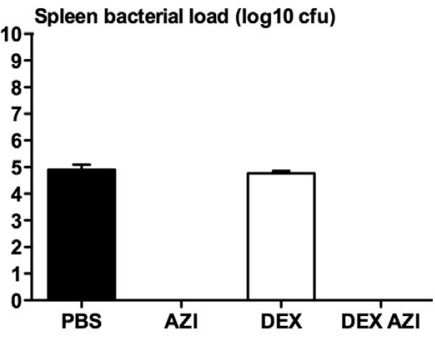

C

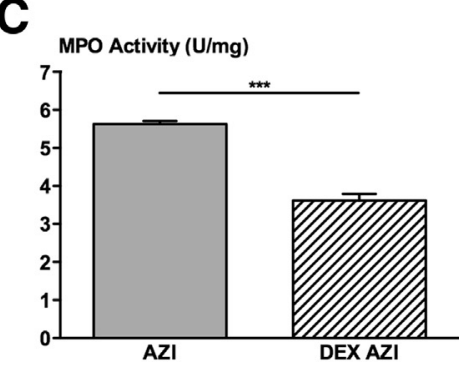

Figure 6 Combined antibiotic and corticosteroid treatment markedly decreases bacterial load, neutrophil influx, and activation in the lungs of dualinfected mice. A: Lung and spleen bacterial load was measured with a CFU assay. B: Total neutrophil numbers in the BAL and lungs were assessed by flow cytometry. C: Neutrophil activation was measured with an MPO assay of lung homogenates at 54 hours after Streptococcus ( $n=3$ per group). Data are expressed as means \pm SEM. ${ }^{*} P<0.05,{ }^{*} P<0.01$, and ${ }^{* * *} P<0.001$.

responses (Figures 5-7), DEX alone hardly improved lung immunopathology (Figure 8C). Overall, the previously described results indicate the following: i) multiple cellular and molecular mechanisms are involved in increased immunopathology during superinfection, and targeting a single pathway will be ineffective; ii) the significant improvement in lung immunopathology and clinical outcome in Flu/Strep hosts requires the effective control of both bacterial infection and host immune responses; and iii) bacterial clearance and lung immunopathology can be two uncoupled, independently regulated processes. Thus, clinically effective control of bacterial infection alone may not lead to markedly improved lung immunopathology in dualinfected hosts.

\section{Discussion}

Secondary bacterial superinfections after influenza are major contributors to hospitalizations and mortality. With increasing bacterial antibiotic resistance and a continuous threat of an influenza virus pandemic, well-developed protocols to fight such heterologous infections must be in place. ${ }^{1,4-6}$ More important, the severely exacerbated lung immunopathology associated with bacterial superinfections must be addressed during treatment. ${ }^{6,13-16,32}$ Also, the underlying mechanisms of such excessive immunopathology need to be further investigated. ${ }^{6,8,17-19}$ By using a mouse model of acute respiratory tract influenza infection and $S$. pneumoniae superinfection, we have investigated these questions. We show that uncontrolled bacterial outgrowth and systemic dissemination, as well as dysregulated host immune responses, including enhanced cytokine and chemokine responses and excessive neutrophil infiltration, are the main contributors to severe lung immunopathology and death. We provide novel information that targeting a single immune cell type or molecular pathway is ineffective. We have identified that the most effective treatment protocol for pneumococcal superinfection after influenza requires both bacteriostatic antibiotic and corticosteroid treatment, and the mere antibiotic control of bacterial infection is ineffective in improving lung immunopathology.

Our model of dual infection, in which mice were infected with a nonlethal dose of influenza, followed 7 days later with a small dose of $S$. pneumoniae, recapitulated the wellestablished clinical observation that influenza infection markedly increases susceptibility to pneumococcal superinfection. The Flu/Strep mice lost $>20 \%$ of body weight and reached $100 \%$ mortality by 72 hours. Consistent with their severe illness and lethality, Flu/Strep mice had significantly higher lung bacterial loads than Strep mice, as well as dissemination to other organs, including the spleen, heart, liver, kidney, and brain. Our further investigation into the potential mechanisms leading to bacterial outgrowth and lethality in Flu/Strep mice showed that cytokine and chemokine responses after streptococcus superinfection were severely dysregulated. In fact, most cytokines and chemokines measured were markedly increased in the Flu/Strep lungs compared with the Strep and Flu alone groups. This corresponded with the observed wide systemic dissemination and rapid weight loss. Enhanced cytokine and chemokine expression has been previously reported in most models of bacterial superinfection after influenza, whereas some studies have also reported influenza-induced defects in 

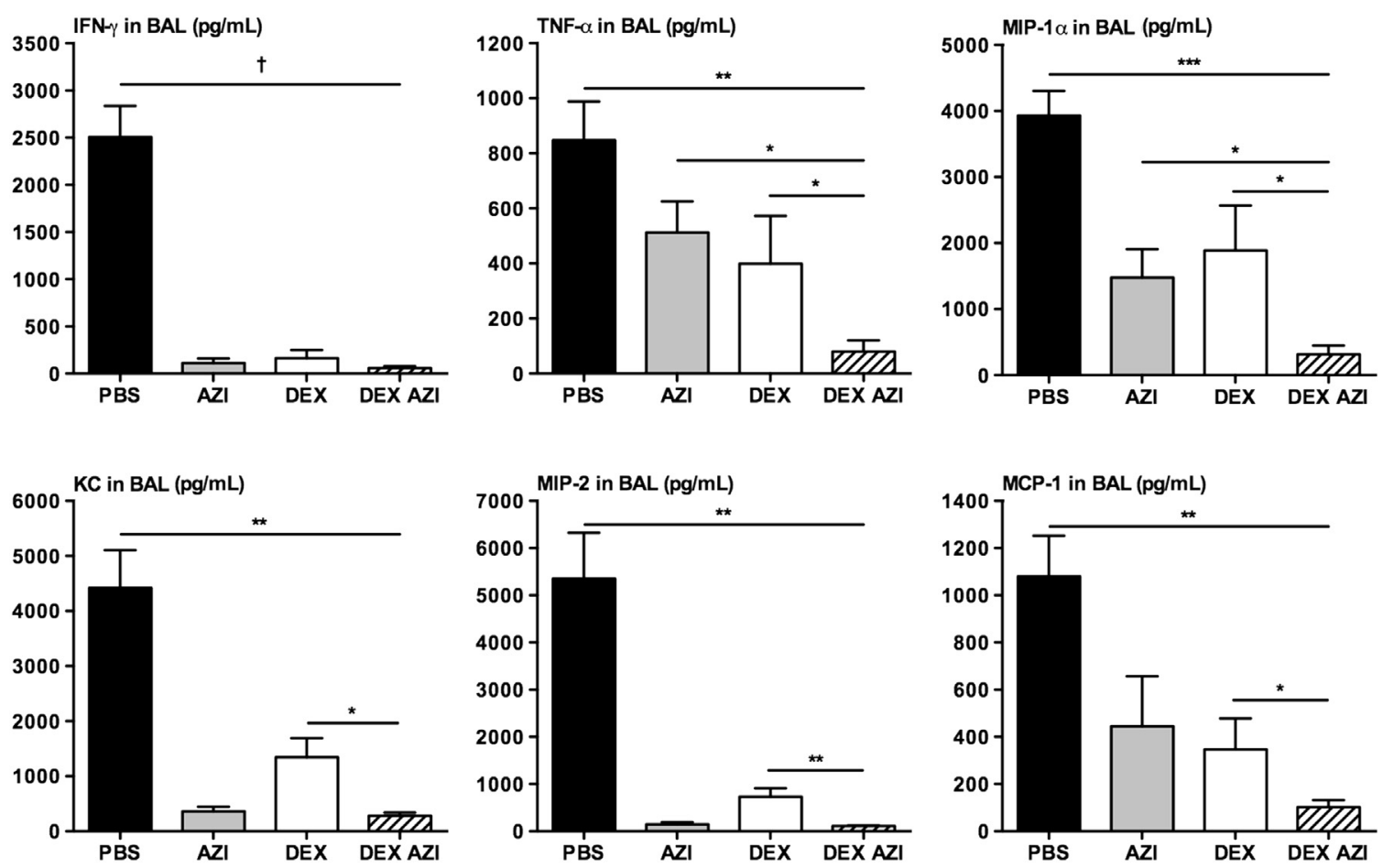

Figure 7 Combined antibiotic and corticosteroid treatment decreases cytokine and chemokine responses in the lungs of dual-infected mice. Cytokine and chemokine levels in BAL fluids were measured. Results are from two to three experiments ( $n=11$ to 15 per group). Data are expressed as means \pm SEM. ${ }^{*} P<0.05,{ }^{* *} P<0.01,{ }^{* * *} P<0.001$, and ${ }^{\dagger} P<0.0005$.

cytokine and chemokine expression. ${ }^{33-36}$ Ongoing inflammatory responses to influenza and the resulting cytokine storm have been suggested to be one of the mechanisms for exacerbated lung immunopathology after bacterial superinfection, and our model supports this notion. ${ }^{1,6}$ In addition, enhanced chemokine responses have been shown to lead to excessive inflammatory cell infiltration, particularly that of neutrophils. ${ }^{17-19,33,37,38}$ In our model, excessive neutrophil influx was observed in Flu/Strep mice corresponding to highly expressed KC and MIP-2 chemokines, which were the two most induced analytes measured. Also, in accordance with previous observations, neutrophil functionality, measured by MPO activity and bacterial phagocytosis, was impaired in the Flu/Strep mice. ${ }^{19,33,36,39}$ Thus, the overwhelming number of neutrophils in the lung, some of which were not functional at clearing the bacteria, contributed to lung immunopathology and ill-controlled bacterial infection.

In our study, we addressed the largely understudied mechanisms of increased immunopathology after bacterial superinfection. As was previously observed in other models, bacterial superinfection after influenza caused severe lung immunopathology and tissue injury, with excessive neutrophilia, large areas of consolidation, degeneration of airway epithelium, hemorrhaging, and plugged airways. ${ }^{8,19,37}$ However, questions still remain about whether the poor clinical outcome after superinfection is due to lung immunopathology, uncontrolled bacterial replication and dissemination, or both. ${ }^{6}$ Uncoupling these factors or processes proved to be difficult in the past. We found that neutralization of the neutrophil chemokine, MIP-2, did not affect bacterial burden, and did not improve clinical outcome or affect lung immunopathology. These results suggest that the highly induced chemokines, including $\mathrm{KC}$, played a compensatory role in recruiting neutrophils into the lung, and together with the cytokine storm and the bacterial outgrowth caused lethality in the Flu/Strep mice. We then depleted neutrophils and found that this did not change bacterial loads either, further showing that the excessive neutrophil numbers in the lung are not helpful in clearing the infection, especially because these cells were shown to be partially functionally impaired. This is in agreement with a study by McNamee and Harmsen, ${ }^{36}$ which showed that a 6-day infection with influenza impaired neutrophil function to such a degree that depleting neutrophils at this point had no effect on bacterial loads. However, neutrophil depletion did result in modestly to moderately improved immunopathology, illustrating that lung immunopathology is dependent, in part, on neutrophil influx. Because clinical outcome was not improved in neutrophil-depleted hosts, bacterial outgrowth and systemic dissemination appeared to be the important factors for mortality. Therefore, we next investigated a treatment protocol involving antibiotic use to clear the bacteria beginning at 30 hours after Streptococcus, when marked lung immunopathology was clearly observed in Flu/Strep mice. We used a nonlytic, bacteriostatic, macrolide antibiotic, AZI, because studies have shown that treatment with bactericidal $\beta$-lactam antibiotics can worsen clinical outcome and pathology. ${ }^{6,20-22}$ All 

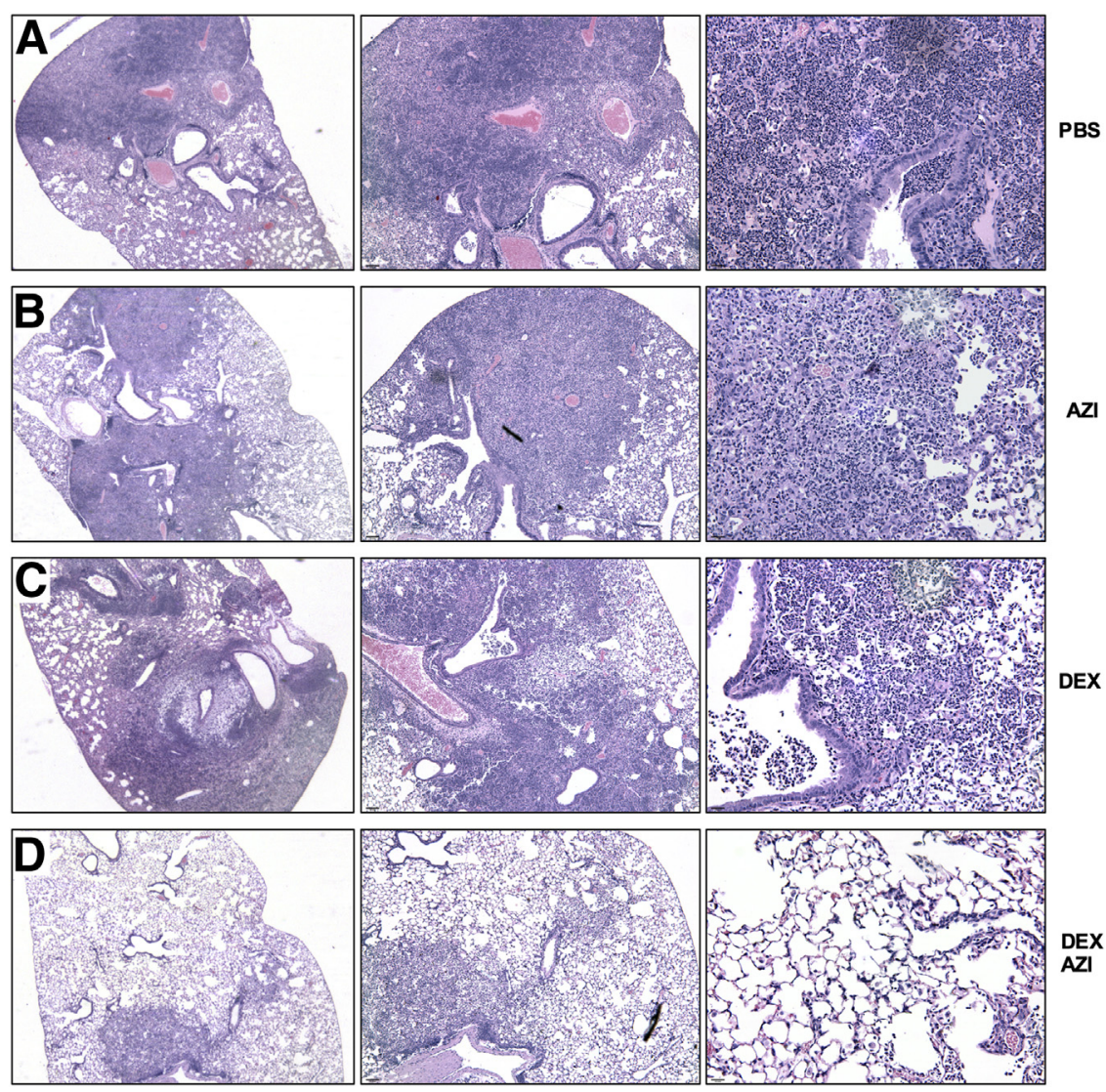

Figure 8 Combined antibiotic and corticosteroid treatment markedly improves lung immunopathology in dual-infected mice. Histopathological changes were examined in the lungs of PBS (A), AZI (B), DEX (C), and DEX/AZI (D) treated mice. Original magnification: $\times 1.6$ (left panels); $\times 5$ (middle panels); $\times 20$ (right panels). Results are from two to three experiments $(n=12$ per group).
AZI-treated mice eventually significantly recovered, and expectedly had markedly decreased bacterial burden in the lungs, with no systemic bacterial dissemination, but demonstrated only moderately reduced cytokine responses and neutrophilia in the lungs. Thus, marked lung immunopathology was still observed in AZI-treated mice and sustained even to later time points after bacteria were fully cleared. This is an important observation, and it, for the first time to our knowledge, uncouples bacterial infection and lung immunopathology in Flu/Strep animals. During an infection, the immune system mounts a response to clear the pathogen, which can, in turn, cause immunopathology. Often, the immunopathogenic processes are closely intertwined with pathogen growth and the two are difficultly unbraided. Their uncoupling can assist in the design of intervention strategies to effectively control both factors. In our model, we have

Table 3 Semiquantification of Histopathological Changes in the Lung after AZI and DEX

\begin{tabular}{lllll}
\hline Variable & PBS & AZI & DEX & DEX AZI \\
\hline Neutrophilia & +++++ & +++ & +++++ & + \\
Inflammation & +++++ & ++++ & +++++ & + \\
Injury & +++++ & ++++ & +++++ & + \\
\hline
\end{tabular}

Tissue neutrophilia, overall lung inflammation, and lung injury were assessed in control (PBS) or treated Flu/Strep mice at 60 hours after Streptococcus. Results are representative of two to three experiments ( $n=12$ mice per group).

+ , Minimal; +++ , moderate; ++++ , marked; +++++ , severe. uncoupled bacterial replication and lung immunopathology by showing that, although the use of antibiotic markedly improved S. pneumoniae clearance, it did not halt the immunopathogenic process. The moderately improved clinical outcome (body weight) observed with the AZI-treated mice appears to be in disaccord with significant lung immunopathology. It is likely that the readout of weight changes does not accurately reflect the status of respiratory tract function, which would be expected to be more sensitively affected by the extent of lung immunopathology. Because unresolved lung pathology can cause chronic obstructive pulmonary disease after the infectious agents are cleared, we modified the treatment protocol to include the corticosteroid, DEX. Although corticosteroids are used in influenza infection and community-acquired pneumonia, there is no consensus on their benefit, particularly in cases of secondary bacterial superinfection, and use of corticosteroids in animal models of dual infection has been scarcely attempted. ${ }^{23-29,40}$ In our study, we show that, although DEX treatment alone did not improve survival, DEX/AZI-treated mice had the quickest recovery, showing that the clinical outcome is most efficiently improved by treatment with both AZI and DEX. Furthermore, DEX/AZI mice had the most significantly decreased bacterial burden in the lungs, with no systemic dissemination, no excessive neutrophil influx into the lungs, and the lowest MPO activity and cytokine/chemokine expression of all of the groups. More importantly, vast improvement of lung immunopathology was seen only in DEX/AZI-treated mice when 
compared with the AZI or DEX alone treated animals. The acute nature of the murine model entails only a short course of DEX treatment. When corticosteroids are applied to human cases, a longer-term protocol may be required, which may potentially increase the risk of opportunistic infections.

In conclusion, our results indicate that both the clinical outcome and severe lung immunopathology are most efficiently improved only by treatment with both antibiotic and corticosteroid, and antibiotic treatment alone is insufficient. In other words, marked improvement of severe lung immunopathology and illness caused by influenza-associated pneumococcal superinfection cannot be accomplished unless both bacterial infection and host immune responses are under effective control. Our findings hold important implications in future clinical practice. During influenza epidemics and pandemics, well-developed protocols must be in place to fight bacterial superinfections, which are the largest contributors to hospitalizations and mortality of otherwise healthy patients. Although antibiotic treatment will remain essential in clinical practice, concurrent use of corticosteroids is imperative in preventing complicating lung immunopathology and injury.

\section{Acknowledgments}

We thank Dr. Earl G. Brown for providing the influenza virus; Dr. Dawn Bowdish, Alicja Puchta, and Dr. Mark Dessing for help with protocols for the growth of S. pneumoniae; and Dr. Waliul I. Khan and Janice Kim for the MPO assay protocol.

\section{Supplemental Data}

Supplemental material for this article can be found at http://dx.doi.org/10.1016/j.ajpath.2013.05.016.

\section{References}

1. McCullers JA: Insights into the interaction between influenza virus and pneumococcus. Clin Microbiol Rev 2006, 19:571-582

2. Didierlaurent A, Goulding J, Hussell T: The impact of successive infections on the lung microenvironment. Immunology 2007, 122: 457-465

3. Morens DM, Taubenberger JK, Fauci AS: Predominant role of bacterial pneumonia as a cause of death in pandemic influenza: implications for pandemic influenza preparedness. J Infect Dis 2008, 198:962-970

4. Brundage JF: Interactions between influenza and bacterial respiratory pathogens: implications for pandemic preparedness. Lancet Infect Dis 2006, 6:303-312

5. Gupta RK, George R, Nguyen-Van-Tam JS: Bacterial pneumonia and pandemic influenza planning. Emerg Infect Dis 2008, 14:1187-1192

6. Damjanovic D, Small CL, Jeyananthan M, McCormick S, Xing Z: Immunopathology in influenza virus infection: uncoupling the friend from foe. Clin Immunol 2012, 144:57-69

7. Damjanovic D, Divangahi M, Kugathasan K, Small CL, Zganiacz A, Brown EG, Hogaboam CM, Gauldie J, Xing Z: Negative regulation of lung inflammation and immunopathology by TNF-alpha during acute influenza infection. Am J Pathol 2011, 179:2963-2976
8. Small CL, Shaler CR, McCormick S, Jeyanathan M, Damjanovic D, Brown EG, Arck P, Jordana M, Kaushic C, Ashkar AA, Xing Z: Influenza infection leads to increased susceptibility to subsequent bacterial superinfection by impairing NK cell responses in the lung. J Immunol 2010, 184:2048-2056

9. Kadioglu A, Andrew PW: The innate immune response to pneumococcal lung infection: the untold story. Trends Immunol 2004, 25: 143-149

10. Paterson GK, Mitchell TJ: Innate immunity and the pneumococcus. Microbiology 2006, 152:285-293

11. Marriott HM, Dockrell DH: The role of the macrophage in lung disease mediated by bacteria. Exp Lung Res 2007, 33:493-505

12. van der Sluijs KF, van der Poll $T$, Lutter R, Juffermans NP, Schultz MJ: Bench-to-bedside review: bacterial pneumonia with influenza - pathogenesis and clinical implications. Crit Care 2010, 14: 219

13. Taubenberger JK, Morens DM: The pathology of influenza virus infections. Annu Rev Pathol 2008, 3:499-522

14. Kuiken T, van den Brand J, van Riel D, Pantin-Jackwood M, Swayne DE: Comparative pathology of select agent influenza a virus infections. Vet Pathol 2010, 47:893-914

15. Hussell T, Wissinger E, Goulding J: Bacterial complications during pandemic influenza infection. Future Microbiol 2009, 4:269-272

16. Brundage JF, Shanks GD: Deaths from bacterial pneumonia during 1918-19 influenza pandemic. Emerg Infect Dis 2008, 14:1193-1199

17. Iverson AR, Boyd KL, McAuley JL, Plano LR, Hart ME, McCullers JA: Influenza virus primes mice for pneumonia from Staphylococcus aureus. J Infect Dis 2011, 203:880-888

18. Heltzer ML, Coffin SE, Maurer K, Bagashev A, Zhang Z, Orange JS, Sullivan KE: Immune dysregulation in severe influenza. J Leukoc Biol 2009, 85:1036-1043

19. Zavitz CC, Bauer CM, Gaschler GJ, Fraser KM, Strieter RM, Hogaboam CM, Stampfli MR: Dysregulated macrophageinflammatory protein-2 expression drives illness in bacterial superinfection of influenza. J Immunol 2010, 184:2001-2013

20. Karlstrom A, Boyd KL, English BK, McCullers JA: Treatment with protein synthesis inhibitors improves outcomes of secondary bacterial pneumonia after influenza. J Infect Dis 2009, 199:311-319

21. Karlstrom A, Heston SM, Boyd KL, Tuomanen EI, McCullers JA: Toll-like receptor 2 mediates fatal immunopathology in mice during treatment of secondary pneumococcal pneumonia following influenza. J Infect Dis 2011, 204:1358-1366

22. Jain S, Kamimoto L, Bramley AM, Schmitz AM, Benoit SR, Louie J, Sugerman DE, Druckenmiller JK, Ritger KA, Chugh R, Jasuja S, Deutscher M, Chen S, Walker JD, Duchin JS, Lett S, Soliva S, Wells EV, Swerdlow D, Uyeki TM, Fiore AE, Olsen SJ, Fry AM, Bridges CB, Finelli L: Hospitalized patients with 2009 H1N1 influenza in the United States: April-June 2009. N Engl J Med 2009, 361: 1935-1944

23. Confalonieri M, Urbino R, Potena A, Piattella M, Parigi P, Puccio G, Della Porta R, Giorgio C, Blasi F, Umberger R, Meduri GU: Hydrocortisone infusion for severe community-acquired pneumonia: a preliminary randomized study. Am J Respir Crit Care Med 2005, $171: 242-248$

24. Han K, Ma H, An X, Su Y, Chen J, Lian Z, Zhao J, Zhu BP, Fontaine RE, Feng Z, Zeng G: Early use of glucocorticoids was a risk factor for critical disease and death from $\mathrm{pH} 1 \mathrm{~N} 1$ infection. Clin Infect Dis 2011, 53:326-333

25. Li C, Yang P, Zhang Y, Sun Y, Wang W, Zou Z, Xing L, Chen Z, Tang C, Guo F, Deng J, Zhao Y, Yan Y, Tang J, Wang X, Jiang C: Corticosteroid treatment ameliorates acute lung injury induced by 2009 swine origin influenza A (H1N1) virus in mice. PLoS One 2012, 7: e44110

26. Meijvis SC, Hardeman H, Remmelts HH, Heijligenberg R, Rijkers GT, van Velzen-Blad H, Voorn GP, van de Garde EM, Endeman H, Grutters JC, Bos WJ, Biesma DH: Dexamethasone and length of hospital stay in patients with community-acquired pneumonia: 
a randomised, double-blind, placebo-controlled trial. Lancet 2011, 377: 2023-2030

27. Remmelts $\mathrm{HH}$, Meijvis SC, Biesma DH, van Velzen-Blad $\mathrm{H}$, Voorn GP, Grutters JC, Bos WJ, Rijkers GT: Dexamethasone downregulates the systemic cytokine response in patients with communityacquired pneumonia. Clin Vaccine Immunol 2012, 19:1532-1538

28. Salluh JI, Povoa P, Soares M, Castro-Faria-Neto HC, Bozza FA, Bozza PT: The role of corticosteroids in severe community-acquired pneumonia: a systematic review. Crit Care 2008, 12:R76

29. Snijders D, Daniels JM, de Graaff CS, van der Werf TS, Boersma WG: Efficacy of corticosteroids in community-acquired pneumonia: a randomized double-blinded clinical trial. Am J Respir Crit Care Med 2010, 181:975-982

30. Brown EG, Bailly JE: Genetic analysis of mouse-adapted influenza A virus identifies roles for the NA, PB1, and PB2 genes in virulence. Virus Res 1999, 61:63-76

31. Motomura Y, Wang H, Deng Y, El-Sharkawy RT, Verdu EF, Khan WI: Helminth antigen-based strategy to ameliorate inflammation in an experimental model of colitis. Clin Exp Immunol 2009, 155:88-95

32. Shieh WJ, Blau DM, Denison AM, Deleon-Carnes M, Adem P, Bhatnagar J, Sumner J, Liu L, Patel M, Batten B, Greer P, Jones T, Smith C, Bartlett J, Montague J, White E, Rollin D, Gao R, Seales C, Jost H, Metcalfe M, Goldsmith CS, Humphrey C, Schmitz A, Drew C, Paddock C, Uyeki TM, Zaki SR: 2009 Pandemic influenza A (H1N1): pathology and pathogenesis of 100 fatal cases in the United States. Am J Pathol 2010, 177:166-175

33. LeVine AM, Koeningsknecht V, Stark JM: Decreased pulmonary clearance of S. pneumoniae following influenza A infection in mice. J Virol Methods 2001, 94:173-186

34. Didierlaurent A, Goulding J, Patel S, Snelgrove R, Low L, Bebien M, Lawrence T, van Rijt LS, Lambrecht BN, Sirard JC, Hussell T:
Sustained desensitization to bacterial Toll-like receptor ligands after resolution of respiratory influenza infection. J Exp Med 2008, 205: 323-329

35. Giamarellos-Bourboulis EJ, Raftogiannis M, Antonopoulou A, Baziaka F, Koutoukas P, Savva A, Kanni T, Georgitsi M, Pistiki A, Tsaganos T, Pelekanos N, Athanassia S, Galani L, Giannitsioti E, Kavatha D, Kontopidou F, Mouktaroudi M, Poulakou G, Sakka V, Panagopoulos P, Papadopoulos A, Kanellakopoulou K, Giamarellou H: Effect of the novel influenza A (H1N1) virus in the human immune system. PLoS One 2009, 4:e8393

36. McNamee LA, Harmsen AG: Both influenza-induced neutrophil dysfunction and neutrophil-independent mechanisms contribute to increased susceptibility to a secondary Streptococcus pneumoniae infection. Infect Immun 2006, 74:6707-6721

37. Smith MW, Schmidt JE, Rehg JE, Orihuela CJ, McCullers JA: Induction of pro- and anti-inflammatory molecules in a mouse model of pneumococcal pneumonia after influenza. Comp Med 2007, 57: 82-89

38. Seki M, Yanagihara K, Higashiyama Y, Fukuda Y, Kaneko Y, Ohno H, Miyazaki Y, Hirakata Y, Tomono K, Kadota J, Tashiro T, Kohno S: Immunokinetics in severe pneumonia due to influenza virus and bacteria coinfection in mice. Eur Respir J 2004, 24 : $143-149$

39. van der Sluijs KF, van Elden LJ, Nijhuis M, Schuurman R, Pater JM, Florquin S, Goldman M, Jansen HM, Lutter R, van der Poll T: IL-10 is an important mediator of the enhanced susceptibility to pneumococcal pneumonia after influenza infection. J Immunol 2004, 172:7603-7609

40. Parra A, Garcia-Olmos M, Nieto E, Garcia-Calvo G, Ponte C, Soriano F: Effect of dexamethasone and pentoxifylline in combination with amoxicillin in the treatment of penicillin-insensitive pneumococcal pneumonia in guinea pigs. Infection 2002, 30:150-156 